\title{
Unusual Rearrangement-Remercuration Reactions of Allylic Silanols
}

Received 00th January 20xx, Accepted 00th January 20xx DOI: $10.1039 / x 0 x \times 00000 x$

\author{
Someshwar Nagamalla ${ }^{a}$, Ranjeet A. Dhokale ${ }^{a}$, Frederick J. Seidl ${ }^{b}$, Joel T. Mague ${ }^{c}$, and \\ Shyam Sathyamoorthi*
}

We present the first examples of rearrangement reactions of allylic silanol substrates into linear ketone and 5-membered cyclic silanediol organomercurial products. Both reactions are mediated by $\mathrm{Hg}(\mathrm{OTf})_{2}$ but differ in the use of base, solvent, and temperature. The substrate scope of both transformations was explored, and the product organomercurials were shown to be valuable synthons. Mechanistic studies suggest that both products are the result of a series of transformations, cascading in one pot. DFT analysis provides a basis for understanding the rearrangement of a 6-endo intermediate into the 5-exo cyclic silanediol product.

\section{Introduction}

Shinde and Sathyamoorthi (2020)

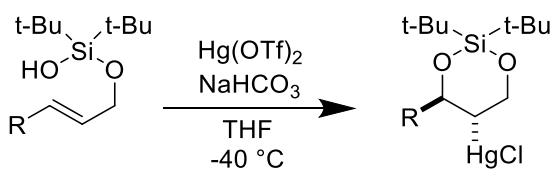

Dhokale, Seidl, and Sathyamoorthi (2021)
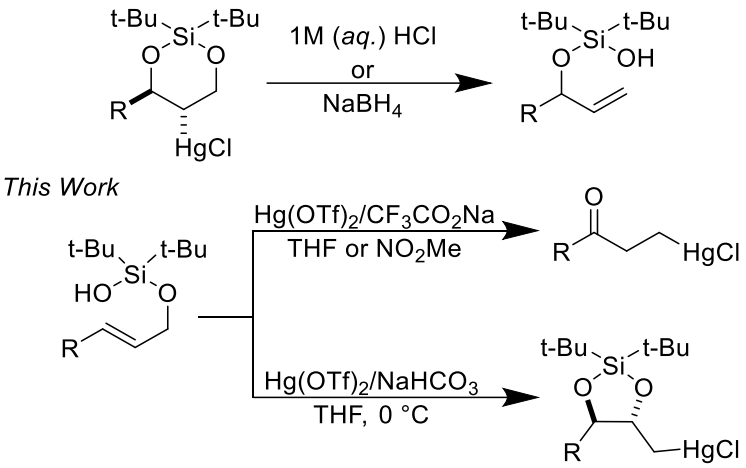

Scheme 1. Careful control of conditions allows for unprecedented rearrangement-remercuration reactions of allylic silanols.

Rearrangement reactions have been a topic of interest to the synthetic community for more than a century, ${ }^{1}$ but only recently have they become a line of investigation in our laboratory. ${ }^{2}$ In general, rearrangements can be demarcated into two categories. One contains true pericyclic processes, which

\footnotetext{
a. Department of Medicinal Chemistry, University of Kansas, Lawrence, Kansas, United States, 66047

b. Independent Researcher, San Mateo, California, United States, 94402

c. Department of Chemistry, Tulane University, New Orleans, Louisiana, United States, 70118

tcorresponding author email: ssathyam@ku.edu

Electronic Supplementary Information (ESI) available: [details of any supplementary information available should be included here]. See DOI: 10.1039/x0xx00000x
}

are concerted and proceed through cyclic transition states ${ }^{3-7}$; such reactions often require vigorous heating or the addition of Lewis acid additives. Another class of rearrangement reactions is comprised of those that proceed through discrete organometallic intermediates. ${ }^{8-12}$

Our laboratory recently disclosed the first rearrangement reaction of primary allylic silanols into secondary ones (Scheme 1). ${ }^{2}$ Strictly speaking, this reaction was a formal rearrangement and required a two-step, two-pot protocol. First, primary allylic silanols were transformed into 6-membered silanediol organomercurial heterocycles using a combination of $\mathrm{Hg}(\mathrm{OTf})_{2}$ and $\mathrm{NaHCO}_{3} .{ }^{13}$ Following purification by silica-gel chromatography, treatment of these heterocycles with $1 \mathrm{M}$ aqueous $\mathrm{HCl}$ in THF or with $\mathrm{NaBH}_{4}$ in DMF allowed for demercurative cleavage into secondary silanol products bearing terminal alkenes.

We sought to develop true, one-pot rearrangement reactions of primary allylic silanol substrates. Our investigations were motivated by both fundamental and applied considerations. Our laboratory has furnished the only precedent for the rearrangements of silanol substrates, and we thus felt that further investigation of this fascinating substrate class $^{14-16}$ was warranted. Furthermore, organomercurial compounds are known valuable synthons (Scheme 2). ${ }^{17,} 18$ The $\mathrm{C}-\mathrm{Hg}$ bond is a highly unusual organometallic linkage with essentially covalent character. ${ }^{19} \mathrm{C}-\mathrm{Hg}$ bonds are known precursors for carbon-centered radicals and can be facilely transformed into $\mathrm{C}-\mathrm{C}, \mathrm{C}-\mathrm{O}$, and $\mathrm{C}-\mathrm{I}$ bonds. ${ }^{20,21}$ We wondered if we could build on our previous work to furnish technology for a rearrangement-remercuration of primary allylic silanols into organomercurial synthons. Here, we are pleased to report that, though careful control of reaction conditions, allylic silanols can be rearranged into 5-membered silanediol organomercurial heterocycles or into linear organomercurial ketones (Scheme 1). To our knowledge, no analogous transformation exists in the literature. 


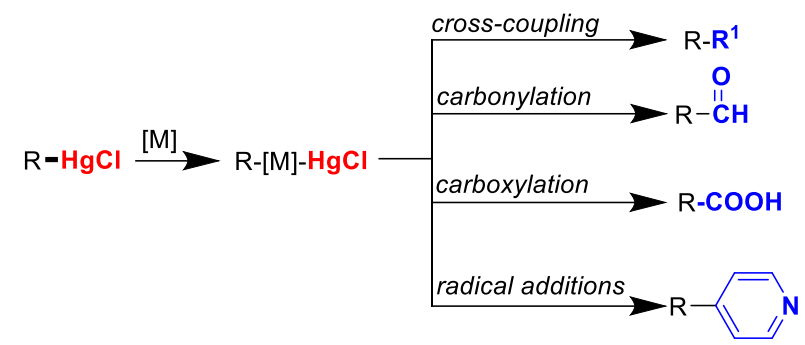

Scheme 2. Organomercury compounds have proven versatility.

\section{Results and Discussion}

\section{Synthetic Studies}

Table 1. Optimization of Ketone Product Formation.

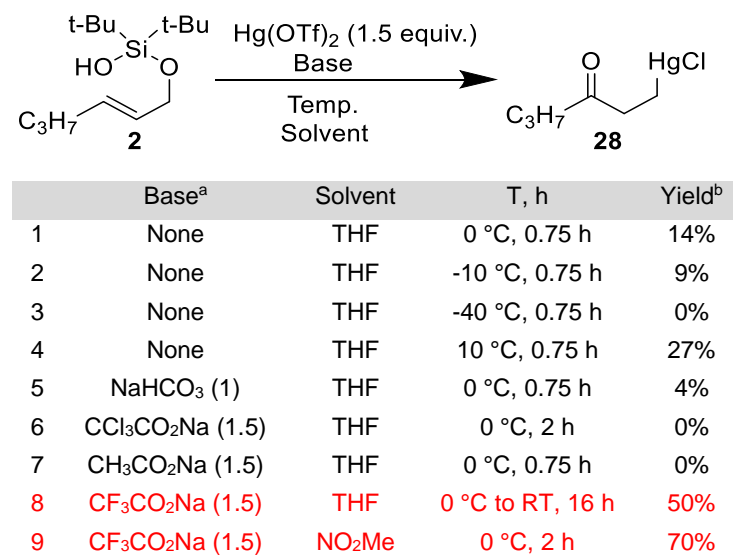

${ }^{a}$ Equivalents are shown in parentheses.

bYield estimated from ${ }^{1} \mathrm{H}$ NMR integration with methyl phenyl sulfone as an internal standard.

Our initial explorations began with (E)-di-tert-butyl(hex-2en-1-yloxy)silanol (Table 1), readily available from condensation of commercially available trans-2-hexen-1-ol with di-tertbutylsilylbis(trifluoromethanesulfonate). ${ }^{13}$ With 1.5 equivalents of $\mathrm{Hg}(\mathrm{OTf})_{2}$ in THF at $0{ }^{\circ} \mathrm{C}$, we were surprised and pleased to isolate approximately $14 \%$ of unusual organomercurial ketone product 28 (Table 1, Entry 1). Dropping the temperature to -10 ${ }^{\circ} \mathrm{C}$ decreased the yield of $\mathbf{2 8}$ to $10 \%$ and further decreasing the temperature to $-40{ }^{\circ} \mathrm{C}$ completely precluded its formation (Table 1, Entries 2-3). Increasing the temperature to $10{ }^{\circ} \mathrm{C}$ was slightly beneficial however (Table 1, Entry 4). $\mathrm{NaHCO}_{3}$, $\mathrm{CCl}_{3} \mathrm{CO}_{2} \mathrm{Na}$, or $\mathrm{CH}_{3} \mathrm{CO}_{2} \mathrm{Na}$ as base additives were invariably deleterious (Table 1, Entries 5-7). A dramatic improvement came with employing $\mathrm{CF}_{3} \mathrm{CO}_{2} \mathrm{Na}$ as a base additive and allowing the reaction temperature to warm to $23{ }^{\circ} \mathrm{C}$ over a period of 16 hours (Table 1, Entry 8). With $\mathrm{CF}_{3} \mathrm{CO}_{2} \mathrm{Na}$, switching the reaction solvent from THF to $\mathrm{NO}_{2} \mathrm{Me}$ and keeping the temperature at 0 ${ }^{\circ} \mathrm{C}$ for 2 hours allowed for still greater product formation (Table 1, Entry 9). We selected the conditions in Table 1, Entry 8 and Table 1, Entry 9 to explore the substrate scope for ketone formation.
Scheme 3. Substrate Scope for Ketone Formation

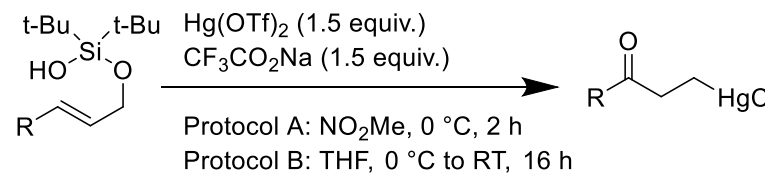

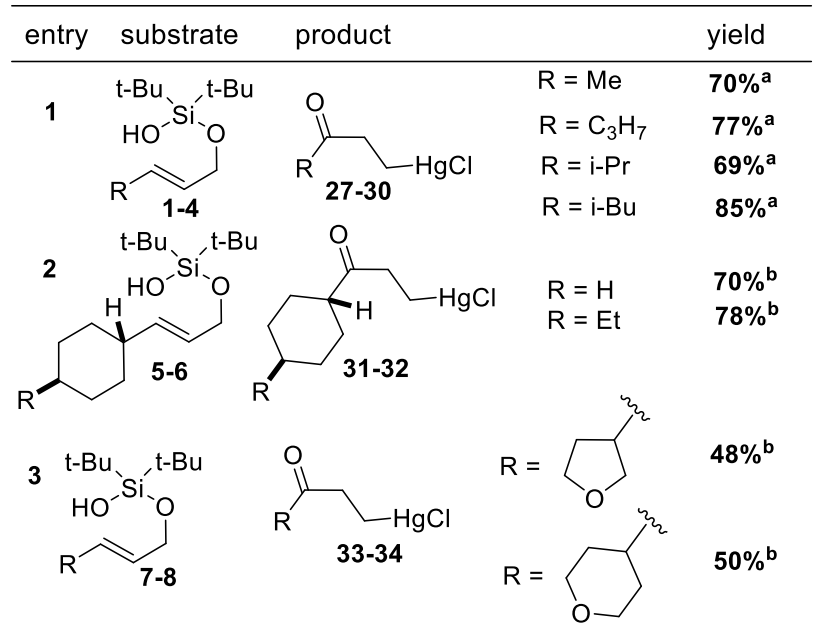

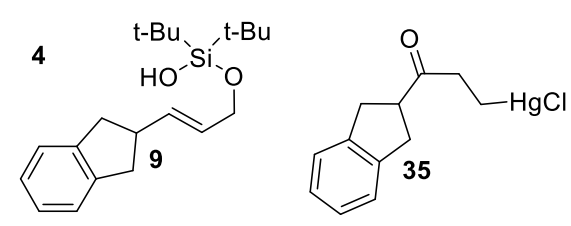

$70 \%^{a}$

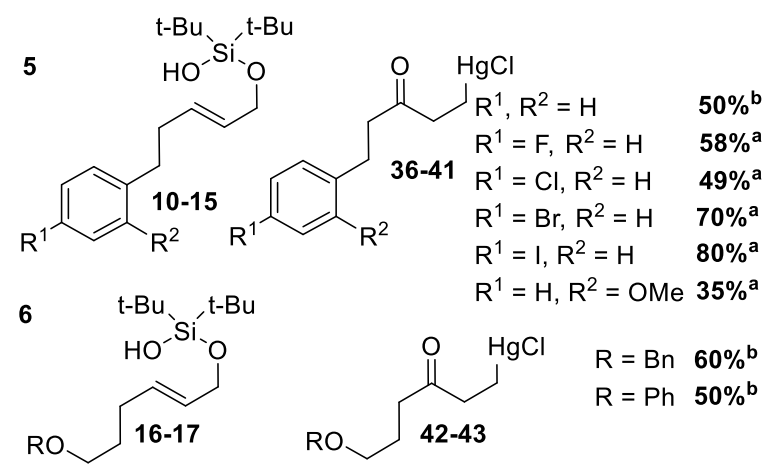

$7 \quad \mathrm{t}-\mathrm{Bu}, \mathrm{t}-\mathrm{Bu}$

$7 \quad \mathrm{HO}^{-} \mathrm{Si}^{\prime} \mathrm{O}$

$\mathrm{C}_{6} \mathrm{H}_{13} \curvearrowright \overbrace{18} \mathrm{D}$<smiles>[2H]C(Cl)C(=O)C(=O)c1ccccc1</smiles>

$80 \%{ }^{a}$<smiles>CC(C)CCCC(C)C/C=C\CO[Si](O)(C(C)(C)C)C(C)(C)C</smiles><smiles>CC(C)CCCC(C)CC(=O)CCCl</smiles>

$72 \%$
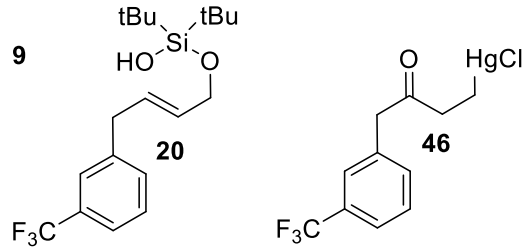

$42 \%$

${ }^{a}$ Reaction performed using Protocol A. ${ }^{b}$ Reaction performed using Protocol B. 
We were pleased to find that our optimized protocols were compatible with a wide array of allylic silanol substrates. Alkyl chains of diverse lengths and branching patterns (Scheme 3, Entries 1, 7, and 8), cyclic hydrocarbons (Scheme 3, Entries 2 and 4), aliphatic ethers (Scheme 3, Entries 3 and 6), aromatic halogens (Scheme 3, Entry 5), aromatic ethers (Scheme 3, Entry 5), and aromatic $\mathrm{CF}_{3}$ groups (Scheme 3, Entry 9) were all tolerated. For substrates not shown here, we recommend empirically testing both protocols $A$ and $B$ for best results.

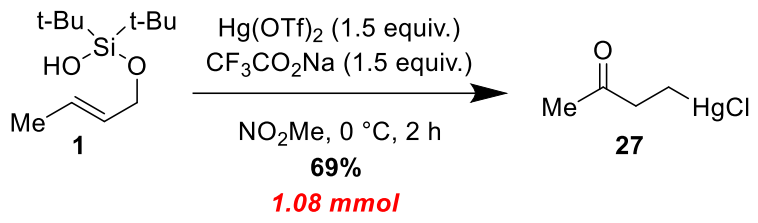

Scheme 4. Ketone formation scales greater than ten-fold without loss of yield.

We were able to scale the ketone formation greater than tenfold without loss of yield or selectivity (Scheme 4).

Furthermore, the product organomercurial ketones were useful synthons for further transformations. Treatment of 39 with triethylamine at room temperature allowed for facile elimination of the $\mathrm{HgCl}$ to form $\alpha, \beta$-unsaturated ketone 47 (Scheme 5A). ${ }^{22}$ Stirring 39 with $\mathrm{I}_{2}$ transformed the $\mathrm{C}-\mathrm{Hg}$ bond into a C-I linkage (Scheme 5B). ${ }^{23,24}$ With $\mathrm{NaBH}_{4}$ in the presence of $1 \mathrm{~atm}$ of $\mathrm{O}_{2}, 25$ diol 49 formed in good yield (Scheme $5 \mathrm{C}$ ); we note that this amounts to a two-pot conversion of readily available allylic alcohols into 1,3-diols, a transformation that has little precedent.
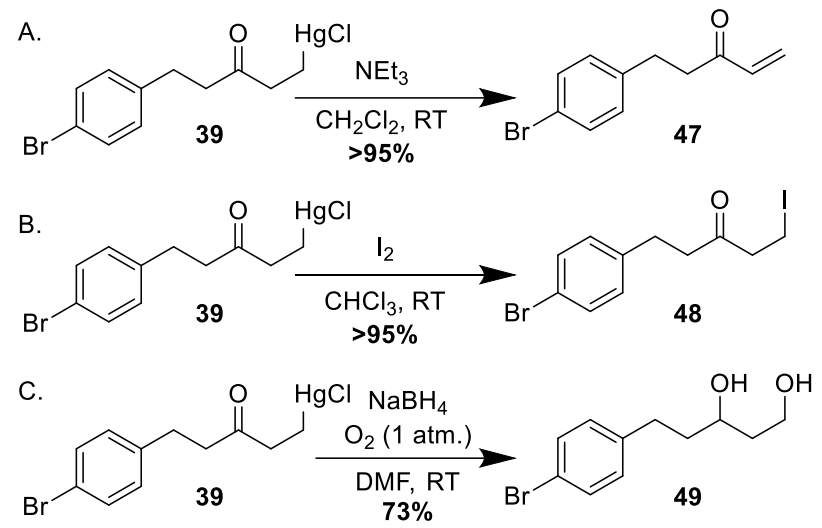

Scheme 5. Ketone organomercurial compounds are versatile synthons for $(A)$ elimination $(B)$ iodination and (C) 1,3-diol formation.

During our optimization process, in some reactions, we isolated small amounts of a side product which we eventually determined to be a 5-membered cyclic silanediol organomercurial compound. We immediately recognized that such intermediates could be extremely valuable in the construction of the functional-group stereochemical arrays found in carbohydrate and polyketide natural products, ${ }^{26}$ and we wondered if we could bias the formation of this product through tuning of reaction conditions (Table 2 ).
Table 2. Optimization of Diol Product Formation

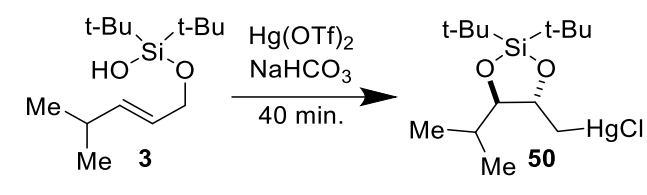

\begin{tabular}{ccccc} 
& $\mathrm{Hg}(\mathrm{OTf})_{2}$ & $\mathrm{NaHCO}_{3}$ & Temp. & Yield $^{\mathrm{a}}$ \\
\hline 1 & 1 equiv. & None & $0{ }^{\circ} \mathrm{C}$ & $39 \%$ \\
2 & 1 equiv. & 1 equiv. & $0{ }^{\circ} \mathrm{C}$ & $48 \%$ \\
3 & 1.5 equiv. & 1.5 equiv. & $0{ }^{\circ} \mathrm{C}$ & $60 \%$ \\
4 & 1.5 equiv. & 1 equiv. & $0{ }^{\circ} \mathrm{C}$ & $70 \%$ \\
5 & 1.5 equiv. & 1 equiv. & $10^{\circ} \mathrm{C}$ & $62 \%$ \\
6 & 1.5 equiv. & 0.75 equiv. & $0{ }^{\circ} \mathrm{C}$ & $60 \%$ \\
7 & 1.5 equiv. & 0.75 equiv. & $-20{ }^{\circ} \mathrm{C}$ & $23 \%$ \\
8 & 1.75 equiv. & 1 equiv. & $0{ }^{\circ} \mathrm{C}$ & $80 \%$
\end{tabular}

aYield estimated from ${ }^{1} \mathrm{H}$ NMR integration with methyl phenyl sulfone as an internal standard.

This turned out not to be as simple a task as we had hoped, but, after some experimentation, we found that 1.75 equivalents of $\mathrm{Hg}(\mathrm{OTf})_{2}$ and 1 equivalent of $\mathrm{NaHCO}_{3}$ in THF at $0{ }^{\circ} \mathrm{C}$ gave silanediol 50 in a respectable yield of $80 \%$ (Table 2, Entry 8) . The ratio of $\mathrm{Hg}(\mathrm{OTf})_{2}$ and $\mathrm{NaHCO}_{3}$ was absolutely critical and small changes (Table 2, Entries 1-5 and 6) led to dramatic variations in yield. Maintaining the reaction temperature at $0{ }^{\circ} \mathrm{C}$ was also crucial; increasing the temperature to $10^{\circ} \mathrm{C}$ was mildly deleterious (Table 1, Entry 5) and dropping the temperature to $-20{ }^{\circ} \mathrm{C}$ (Table 1, Entry 7) was dramatically so.

Our optimized protocol was compatible with several branched alkyl (Scheme 6, Entries 1 and 7), cyclic hydrocarbon (Scheme 6, Entries 2, 5, 6, and 8), and cyclic ether (Scheme 6, Entries 3-4) substrates. We found that diol formation was quite sensitive to the branching pattern of the allylic silanol substrate (Scheme 7). For example, linear alkyl silanols decomposed rapidly into an intractable mixture of products when subjected to a combination of $\mathrm{Hg}(\mathrm{OTf})_{2}$ and $\mathrm{NaHCO}_{3}$ in $\mathrm{THF}$ at $0{ }^{\circ} \mathrm{C}$. For such substrates (Scheme 7A and 7B), an alternate protocol of $\mathrm{Hg}(\mathrm{OTf})_{2} / \mathrm{CF}_{3} \mathrm{CO}_{2} \mathrm{Na}$ in THF was required to stabilize diol formation. Likewise, our standard optimized protocol failed for substrates with aromatic rings $\alpha$ to the alkene (Scheme 7C and 7D). For such substrates, using conditions for 6-membered cyclic silanediol formation ${ }^{13}$ followed by warming the reaction flask to room temperature over a period of 6 hours allowed for reasonable yields of the desired five-membered products. Crystallization of one these products, 63 (CCDC: 2084035), allowed us to establish the relative stereochemistry of the silanediol heterocycle. 
Scheme 6. Substrate Scope for Diol Formation.

$$
\begin{gathered}
\mathrm{NaHCO}(1 \text { equiv. }) \\
\mathrm{THF}, 0{ }^{\circ} \mathrm{C}, 40 \text { min. }
\end{gathered}
$$

\begin{tabular}{|c|c|c|c|}
\hline entry & substrate & product & yield \\
\hline
\end{tabular}

1 急-4<smiles>[R]C1CCC(/C=C/CO[Si](C)(C)C(C)(C)C)CC1[Z16]</smiles>

3<smiles></smiles><smiles>CC(C)(C)[Si](O)(OC/C=C/C1CCOCC1)C(C)(C)C</smiles><smiles>CC(C)(C)[Si](O)(COCC=CC1Cc2ccccc2C1)C(C)(C)C</smiles>

6<smiles>CC(C)(C)[Si](O)(OCC=[C+]C1CCCC1)C(C)(C)C</smiles><smiles>CCC(C)C=CCO[Si](O)(C(C)(C)C)C(C)(C)C</smiles><smiles>CC(C)(C)[Si](O)(OCC1CCc2ccccc2C1)C(C)(C)C</smiles>

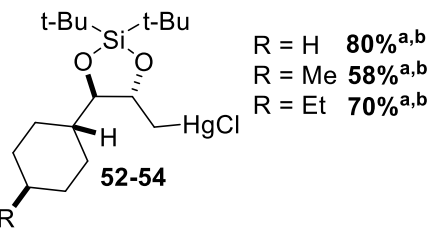

$\mathrm{t}-\mathrm{Bu} \overline{\mathrm{Si}}^{-\mathrm{t}-\mathrm{Bu}}$<smiles>ClCC[C@H]1OCOC1C1CCOC1</smiles>

$40 \%$, d<smiles></smiles><smiles>CC[C@H]1O[Si](C)OC1C1CCOCC1</smiles>

$45 \%^{a, c}$

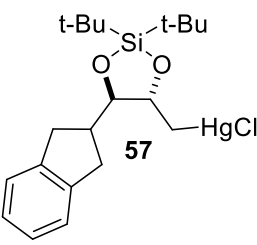

$48 \%^{a, c}$<smiles>CC(C)(C)[Si](OC(C[Hg]Cl)C1CCCC1)(C(C)(C)C)C(C)(C)C</smiles>

$57 \%^{a, b}$<smiles>CCCCCC[C@@H]1O[Si](C(C)(C)C)(C(C)(C)C)OC1C(C)CC</smiles>

$72 \% \mathrm{c}$ $d r=1.5: 1$<smiles>CC(C)(C)[Si]1(C(C)(C)C)O[C@@H](C2CCc3ccccc3C2)[C@@H](CCCl)O1</smiles>

mixture of diastereomers

$50 \%^{\mathrm{b}}$

${ }^{a}$ single trans diastereomer (racemic)

$\mathrm{b}_{1.75}$ equiv. of $\mathrm{Hg}(\mathrm{OTf})_{2}$

c2.5 equiv. of $\mathrm{Hg}(\mathrm{OTf})_{2}$

${ }^{d}$ single diastereomer, relative stereochemistry unassigned (racemic)
A.

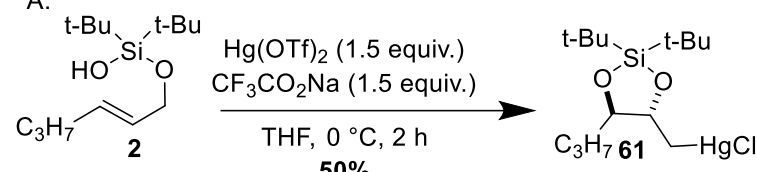

B. $50 \%$

$$
\begin{aligned}
& \text { t-Bu, }{ }^{\mathrm{t}-\mathrm{Bu}} \mathrm{Hg}(\mathrm{OTf})_{2}\left(1.5 \text { equiv.) } \quad \mathrm{t}-\mathrm{Bu}{ }^{-} \mathrm{Si}^{-\mathrm{t}-\mathrm{Bu}}\right.
\end{aligned}
$$

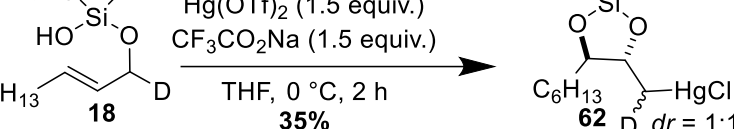

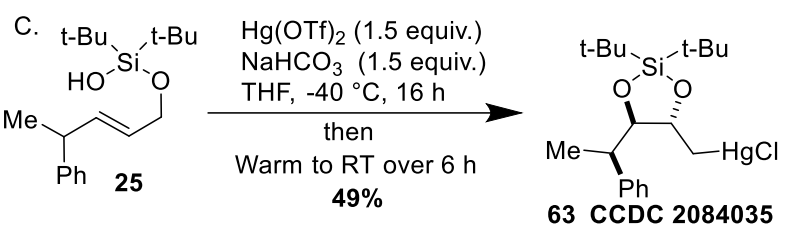<smiles>CC(c1ccc(C(C)(C)C)cc1)C1O[Si](C(C)(C)C)(C(C)(C)C)O[C@H]1CCCl</smiles>

Scheme 7. Certain substrates require special conditions for diol formation.

\section{Mechanistic Studies}

We hypothesized that both diol and ketone organomercurial products were the result of a series of reactions, cascading in one-pot (Scheme 8A). Our previous work with the formation of 6-membered cyclic silanediol organomercurials ${ }^{13}$ and their ring opening using either $1 \mathrm{M} \mathrm{HCl}$ in THF or $\mathrm{NaBH}_{4}$ in $\mathrm{DMF}^{2}, 27$ laid the foundation for our continued mechanistic investigations. We have previously established 6-membered organomercurial compounds such as 65 are facilely opened in the presence of acid to form rearranged allylic silanol compounds such as $\mathbf{6 6}$. Diastereoselective, 5-exo-ring closure would form silanediol 67. Intramolecular attack by the pendant mercury species would form transient mercuronium 68; elimination would form silyl enol ether $\mathbf{6 9}$, which could collapse into ketone product $\mathbf{7 0}$.

To explore the plausibility of this pathway, we synthesized several of our proposed intermediates and subjected them to reaction conditions which we imagine simulate what they encounter in the flask. Treating $\mathbf{7 1}$ with a mixture of $\mathrm{Hg}(\mathrm{OTf})_{2}$ and $\mathrm{CF}_{3} \mathrm{CO}_{2} \mathrm{H}$ led to formation of 5-membered silanediol $\mathbf{6 1}$ and ketone 28 in a 2:1 ratio (Scheme 8B). When $\mathrm{Hg}(\mathrm{OTf})_{2}$ was omitted (Scheme $\mathbf{8 C}$ ), allylic silanols $\mathbf{6 6}$ and $\mathbf{2}$ formed. When 5membered silanediol $\mathbf{6 1}$ was stirred in the presence of $\mathrm{Hg}(\mathrm{OTf})_{2}$ and $\mathrm{CF}_{3} \mathrm{CO}_{2} \mathrm{H}$, ketone product 28 formed (Scheme 8D). Collectively, these experiments established the competence of several of our proposed intermediates to form species downstream in the reaction cascade. 
A. Proposed Mechanistic Pathway

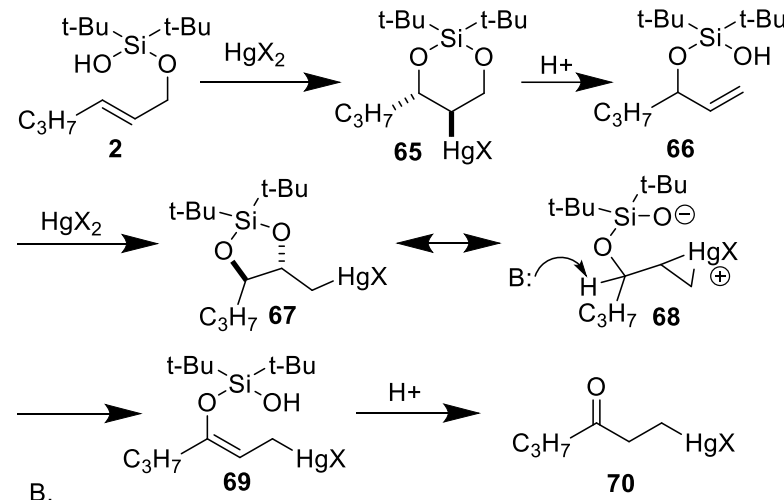

B.

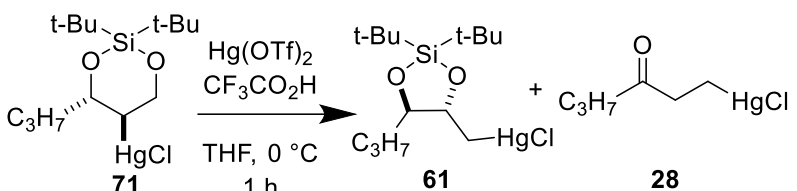

(2:1 ratio)

$$
\text { D. }
$$

Scheme 8. Proposed mechanistic pathway and supporting experiments.

\section{DFT Analysis}

Why does the 6-endo intermediate rearrange into the 5-exo product? We turned to computational studies using the ORCA DFT software package 28,29 to rationalize the observed preference for a rearranged 5-membered ring $\mathbf{7 3}$ versus the initially formed 6-membered ring 72. All calculations were performed using the B3LYP30, 31 functional with D3BJ dispersion correction $^{32,}{ }^{33}$ using the RIJCOSX approximation. ${ }^{34}$ The def2TZVP basis set ${ }^{35}$ was used, and implicit THF solvation was applied using the SMD model. ${ }^{36}$ The def2-ECP ${ }^{37}$ was applied automatically to mercury replacing 60 core electrons. Further details and atomic coordinates are reported in the Supporting Information.

Prior computational studies by our group have shown that related mercuronium rearrangements on these substrates proceed with relatively low barriers $(\sim 10 \mathrm{kcal} / \mathrm{mol})$ and are under thermodynamic control. ${ }^{2}$ Therefore, we sought to understand the selectivity in terms of the relative energies of organomercury ground states. Starting with organomercuric chlorides for computational ease, there was a small $\Delta G$ of 0.51 $\mathrm{kcal} / \mathrm{mol}$ favoring the 5-exo rearranged product 73 over the initial 6-endo intermediate $\mathbf{7 2}$ (Figure 1). However, for organomercuric triflates, $\Delta \mathrm{G}$ grew to $1.94 \mathrm{kcal} / \mathrm{mol}$, again favoring 73-OTf over 72-OTf. Note that the mercuric

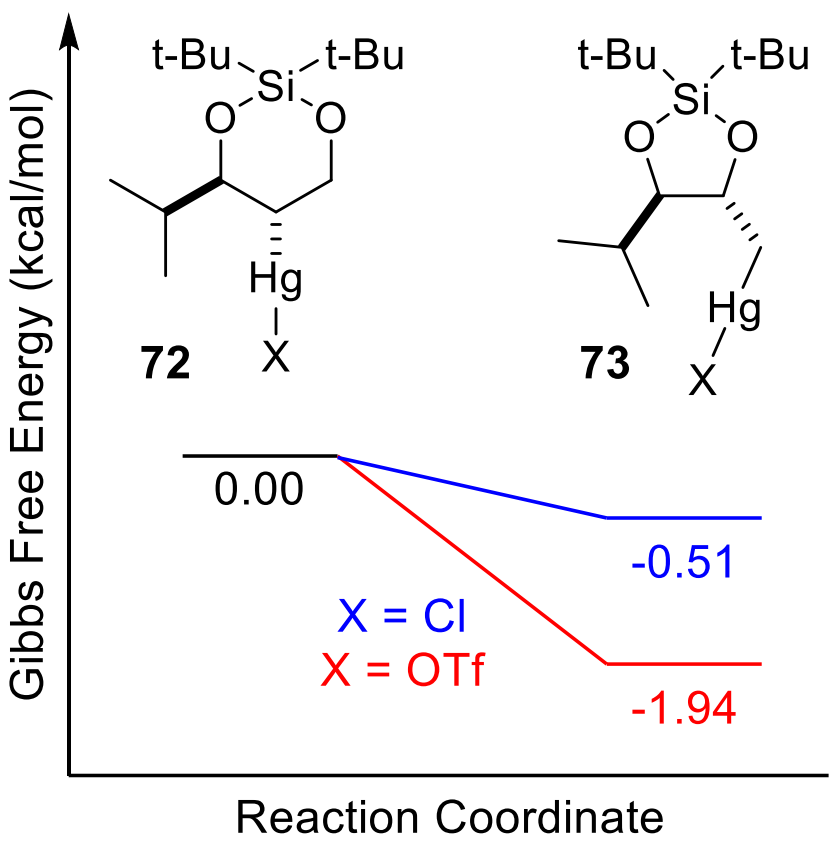

Figure 1: Relative DFT energies of 5-exo versus 6-endo mercuric chlorides and triflates.

triflate is the more relevant reaction intermediate, whereas the inert mercuric chloride is only present after quenching the reaction with brine. From a $\Delta \mathrm{G}$ of $1.94 \mathrm{kcal} / \mathrm{mol}$, a Boltzmann population analysis (Equation 1) at $0{ }^{\circ} \mathrm{C}$ corresponds to a 97.2 : 2.8 (or 34:1) ratio favoring $\mathbf{7 3}$. This agrees well with observed selectivity in which $\mathbf{7 2}$ is not seen at all, perhaps due to alternative decomposition pathways.

Equation 1: $\quad \frac{A}{B}=\exp \frac{E(A)-E(B)}{k T}$

Interestingly, the calculated molecular dipole of the organomercuric chlorides was approximately 3.5 Debye, whereas that of the organomercuric triflates was about 7.5 Debye. This speaks to a greater ionic character for the organomercuric triflate species, which no doubt contributes to its reactivity, and may be the underlying reason for the observed selectivity. We analyzed the molecular orbitals to better quantify this polar effect. In the extensively delocalized HOMO of each organomercurial triflate, hyperconjugation of one or both silanol oxygen lone pairs into the $\sigma^{*}$ of the $\mathrm{C}-\mathrm{Hg}$ bond is observed (Figure 2). The HOMO of the 5-exo rearranged product 73-OTf is lower in energy than that of the 6-endo intermediate $72-0 T f$ by $1.47 \mathrm{kcal} / \mathrm{mol}$. It follows that the presence of an additional silanol oxygen lone pair has a destabilizing effect on the HOMO for the 6-endo intermediate, which may be the ultimate driving force for the observed 5-exo selectivity. 


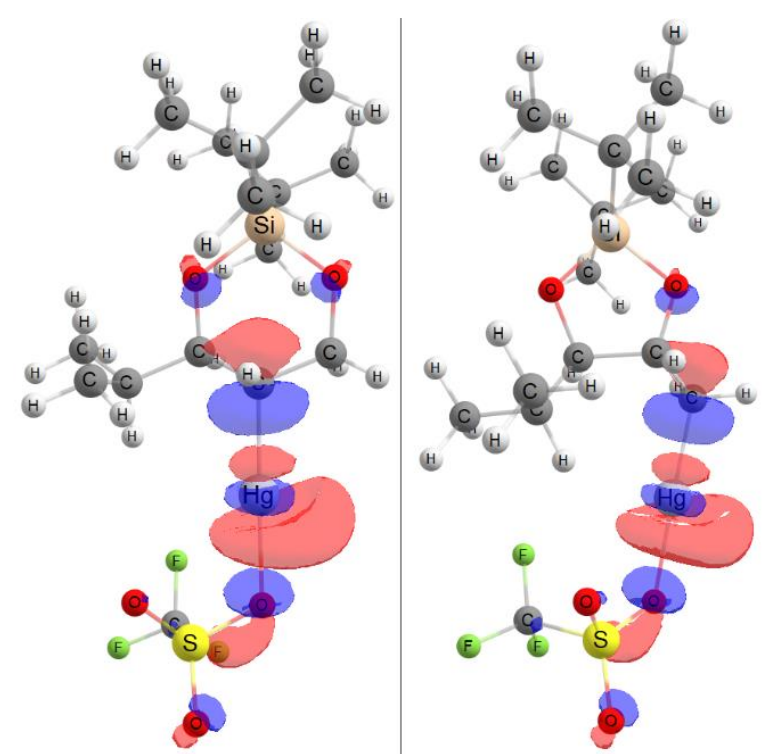

Figure 2: HOMO of 6-endo 72-OTf (left) and 5-exo 73-OTf (right). Isosurface contour value $=0.05$.

\section{Conclusion}

In summary, we present the first examples of rearrangement reactions of allylic silanol substrates into linear ketone and 5-membered cyclic silanediol organomercurial products. Both reactions are mediated by $\mathrm{Hg}(\mathrm{OTf})_{2}$ but differ in the use of base, solvent, and temperature. The substrate scope of both transformations was explored and the product organomercurials were shown to be valuable synthons. Mechanistic studies suggest that both products are the result of a series of transformations, cascading in one pot. DFT analysis provides a basis for understanding the rearrangement of a 6 endo intermediate into the 5-exo cyclic silanediol product. The recent flurry of activity in the area of allylic silanediol transformations promises several more exciting developments in the future.

\section{Conflicts of interest}

There are no conflicts to declare.

\section{Acknowledgements}

This work was supported by start-up funding provided jointly by the University of Kansas Office of the Provost and the Department of Medicinal Chemistry, an NIH COBRE Chemical Biology of Infectious Diseases Research Project Grant (P20GM113117), and a New Faculty General Research Fund Grant.

\section{References}

1. N. Graulich, WIREs Computational Molecular Science, 2011, 1, 172-190.

2. R. A. Dhokale, F. J. Seidl and S. Sathyamoorthi, Molecules, 2021, 26, 3829.
3.

A. M. Martín Castro, Chemical Reviews, 2004, 104, 29393002.

4. H. Ito and T. Taguchi, Chemical Society Reviews, 1999, 28, 43-50.

5. N. Kesava Reddy and S. Chandrasekhar, The Journal of Organic Chemistry, 2013, 78, 3355-3360.

6. Y.-c. Qin, C. E. Stivala and A. Zakarian, Angewandte Chemie International Edition, 2007, 46, 7466-7469.

7. T. J. Fulton, A. Q. Cusumano, E. J. Alexy, Y. E. Du, H. Zhang, K. N. Houk and B. M. Stoltz, Journal of the American Chemical Society, 2020, 142, 21938-21947.

8. L. E. Overman, Tetrahedron, 2009, 65, 6432-6446.

9. L. E. Overman and F. M. Knoll, Tetrahedron Letters, 1979, 20, 321-324.

10. A. T. Herrmann, T. Saito, C. E. Stivala, J. Tom and A. Zakarian, Journal of the American Chemical Society, 2010, 132, 5962-5963.

11. S. Bellemin-Laponnaz, H. Gisie, J. P. Le Ny and J. A. Osborn, Angewandte Chemie International Edition in English, 1997, 36, 976-978.

12. Y. Xie and P. E. Floreancig, Chemical Science, 2011, 2, 2423-2427.

13. A. H. Shinde and S. Sathyamoorthi, Organic Letters, 2020, 22, 8665-8669.

14. R. A. Dhokale, F. J. Seidl, A. H. Shinde, J. T. Mague and S. Sathyamoorthi, The Journal of Organic Chemistry, 2021, DOI: 10.1021/acs.joc.1c00872.

15. Y. Wang and V. Gevorgyan, Angewandte Chemie International Edition, 2015, 54, 2255-2259.

16. A. M. Hardman-Baldwin, M. D. Visco, J. M. Wieting, C. Stern, S.-i. Kondo and A. E. Mattson, Organic Letters, 2016, 18, 3766-3769.

17. S. T. Sarraf and J. L. Leighton, Organic Letters, 2000, 2, 403-405.

18. K. R. Hornberger, C. L. Hamblett and J. L. Leighton, Journal of the American Chemical Society, 2000, 122, 1289412895.

19. R. C. Larock, Angewandte Chemie International Edition in English, 1978, 17, 27-37.

20. R. C. Larock, in Organomercury Compounds in Organic Synthesis, Springer Berlin Heidelberg, Berlin, Heidelberg, 1985, DOI: 10.1007/978-3-642-70004-0_3, pp. 155-186.

21. R. C. Larock, in Organomercury Compounds in Organic Synthesis, Springer Berlin Heidelberg, Berlin, Heidelberg, 1985, DOI: 10.1007/978-3-642-70004-0_4, pp. 187-239.

22. M. A. Larsen, E. T. Hennessy, M. C. Deem, Y.-h. Lam, J. Saurí and A. C. Sather, Journal of the American Chemical Society, 2020, 142, 726-732.

23. A. J. Bloodworth, K. J. Bowyer and J. C. Mitchell, The Journal of Organic Chemistry, 1987, 52, 1124-1128.

24. R. V. Stevens and K. F. Albizati, The Journal of Organic Chemistry, 1985, 50, 632-640.

25. J. K. Khalaf and A. Datta, The Journal of Organic Chemistry, 2004, 69, 387-390.

26. I. Paterson and N. Y. S. Lam, The Journal of Antibiotics, 2018, 71, 215-233.

27. F. G. Bordwell and M. L. Douglass, Journal of the American Chemical Society, 1966, 88, 993-999.

28. F. Neese, WIREs Computational Molecular Science, 2012, 2, 73-78.

29. F. Neese, WIREs Computational Molecular Science, 2018, 8, e1327. 
30. A. D. Becke, The Journal of Chemical Physics, 1993, 98, 1372-1377.

31. C. Lee, W. Yang and R. G. Parr, Physical Review B, 1988, 37, 785-789.

32. S. Grimme, J. Antony, S. Ehrlich and H. Krieg, The Journal of Chemical Physics, 2010, 132, 154104.

33. S. Grimme, S. Ehrlich and L. Goerigk, Journal of Computational Chemistry, 2011, 32, 1456-1465.

34. F. Weigend, Physical Chemistry Chemical Physics, 2006, 8, 1057-1065.

35. F. Weigend and R. Ahlrichs, Physical Chemistry Chemical Physics, 2005, 7, 3297-3305.

36. A. V. Marenich, C. J. Cramer and D. G. Truhlar, The Journal of Physical Chemistry B, 2009, 113, 6378-6396.

37. D. Andrae, U. Häußermann, M. Dolg, H. Stoll and H. Preuß, Theoretica chimica acta, 1990, 77, 123-141. 